This report was prepared as an account of work sponsored by an agency of the United States Government. Neither the United States Government nor any agency thereof, nor any of their employees, makes any warranty, express or implied, or assumes any legal liability or responsibility for the accuracy, completeness, or usefulness of any information, apparatus, product, or process disclosed, or represents that its use would not infringe privately owned rights. Reference herein to any specific commercial product, process, or service by trade name, trademark, manufacturer, or otherwise does not necessarily constitute or imply its endorsement, recommendation, or favoring by the United S'states Government or any agency thereof. The views and opinions of authors expressed herein do not necessarily state or reflect those of the United States Government or any agency thereof.

ANL/CP- 74444

DE92 004723

\title{
Polymerization of Immunoglobulin Dornains: A Model System for the Development of Facilitated Macromolecular Assembly ${ }^{1}$
}

\author{
Fred J. Stevens
}

Elizabeth A. Myatt

Biological and Medical Research Division

Argonne National Laboratory

Argonne, IL 60439-4833

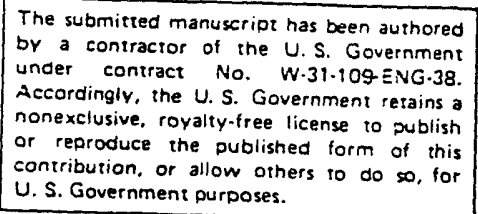

${ }^{1}$ This work was supported by the United States Department of Energy, Office of Health and Environmental Research, under Contract W-31-109-ENG-38. 


\section{ABSTRACT}

We have recently determined that monoclonal immunoglobulin light chains (Bence Jones proteins) are capable of reversible polymerization at room temperature. This property, as exhibited by immunoglobulin light chains (normally a component of an intact antibody molecule), may have novel implications for the development of "molecular nanotechnology."

The polymerization capability of the immunoglobulin light chain is associated with the so-called variable domain of this molecule. The variable domain is a durable, compact beta-sheet structure of molecular weight approximately 12,000 . Humans are capable of producing thousands of different light chain variable domains. Most of the primary sequence variation is limited to one portion of the molecule, that portion associated with the contribution of immunoglobulin light chains to the recognition and binding of thousands of different antigens by antibodies.

As a consequence of these variations, different light chains polymerize with different degrees of avidity, from negligible to extensive. The polymerization process depends on solution parameters such as $\mathrm{pH}$. Thus, polymerization might be induced at one $\mathrm{pH}$ and suppressed or reversed at another. In some cases, Bence Jones proteins in vivo form an insoluble rigid assembly known as amyloid, which might result from lateral docking of two or more polymerized filaments.

The three dimensional structure of these proteins is well known through several crystallographic studies of antibody-like light chain dimers. Likewise, amino acid sequences of hundreds of these proteins have been obtained. Immunoglobulin molecules are readily produced in large quantities in $E$. coli; they are suitable for systematic site-specific mutation that provides for rational engineering to incorporate useful recognition and physical-chemical features. Combinations of molecules of appropriate specificities could assemble into structures of predeter- 
mined three-dimensional forms and properties.

These features suggest that Bence Jones proteins represent a powerful model system within which to develop empirical rules relevant to a technology of proteinbased "construction." Development of these rules will require the combined efforts of biophysical and crystallographic studies, protein engineering, and molecular modeling. 


\section{INTRODUCTION}

The antibody molecule is the detection device of the immune systems of vertebrate organisms, binding to bacteria, viruses, and other "non-self" molecules. Attachment of antibodies labels these inappropriate elements as "foreign" and initiates further immunological responses for their removal. Evolution has provided an efficient detection system by devising a diverse antibody repertoire capable of recognizing an estimated millions of complementary molecular structures (for reviews, see Chothia et al. 1989; Davies et al. 1990).

A large contribution to this diversity is accomplished by the fact that the antigen binding site of an antibody is constructed by the combination of two independently synthesized polypeptide chains, a "light" chain and a larger "heavy" chain. Therefore, to a first approximation, the number of physiologically possible different structures of antigen binding sites is determined by the product of the number of different light chains and heavy chains the organism is capable of producing.

The antibody light chain, which is the subject of our discussion, is a protein composed of two independent " $\beta$-barrel" domains, each consisting of $110-120$ amino acids, for a combined molecular weight of $c a .23,000$. The domain located at the aminoterminus of the protein is encoded by a large number of gene exons, in contrast to the limited number of exons that encode the carboxyterminal domain. Additional amino acid substitutions in the amino-terminal domain occur as a result of mutations that accumulate during the lifetime of the organism. Consequently, the amino acid sequences of the amino-terminal domains are very heterogeneous, whereas the sequences of the carboxy-terminal domains are comparatively conserved. These domains are known as the variable domain and the constant domain, respectively. A similar organizational pattern is found for the heavy chain. In the intact antibody, the juxtaposition of the variable domains of both light and heavy chain account for the diversity of the antioody repertoire. 
Antibodies are synthesized and secreted by a specialized blood cell known as a plasma cell; an individual plasma cell can produce only one kind of antibody. Multiple myeloma is a cancer of the immune system which results in the formation of tumors of identical plasma cells. Because the synthesis of excess light chains is a normal attribute of the production of antibodies, the presence of these tumors, which are plasma cell clones, generates monoclonal antibody and free morioclonal light chains not combined with heavy chains. The light chains are sufficiently small to be filtered through the kidney and appear in the urine of the patient.

Myeloma-derived light chains, known as Bence Jones proteins (Jones 1847, 1848), provided much of the early structural and genetic insight into the molecular biology of antibodies (for review, see Stevens et al. 1991). Free light chains are capable of self-association, or dimerization, mediated through interaction of their variable domains (Maeda et al. 1976, 1978; Stevens et al. 1980; Stevens and Schiffer 1981). The affinities of dimerization of the monoclonal proteins produced by individual patients vary, reflecting differences in the amino acic sequences. We have recently determined, that under appropriate conditions of $\mathrm{pH}$, ionic strength, and ionic composition, many light chains exhibit higher order aggregation. The propensity for aggregation, and the optimal conditions for aggregation, are determined by the amino acid sequence of each individual protein. The three-dimensional structures of several dimeric Bence Jones proteins have been determined (Schiffer et al. 1973,1989; Epp et al. 1974, 1975; Fehlhammer et al. 1975; Colman et al. 1977; Furey et al. 1979,1983; Abola et al. 1980; Chang et al. 1985; Ely et al. 1985, 1989). These studies have shown, that although the interactions between monomeric $\beta$-domains may be altered by solvent conditions (Chang et al. 1985; Stevens et al. 1988; Ely et al. 1989; Schiffer et al. 1989), or amino acid determinants (Furey 1979,1983), the underlying three-dimensional structure of the $\boldsymbol{\beta}$-domain is highly conserved (Figure 1). Analyses of the structure of one antibody light chain in a third solvent sys- 
tem, as well of the structures for three new light chains, are currently in progress (M. Schiffer, unpublished information). In this report, we discuss the potential of systematic study of this extremely diverse family of structurally homologous proteins, and variants produced by molecular biology methods, to provide new insight into mechanisms for the control of assembly of polypeptide subunits. 


\section{MATERIALS AND METHODS}

\subsection{Proteins.}

Purified human antibody light chains were generously provided by Dr. Alan Solomon, Department of Medicine, University of Tennessee Medical Center, Knoxville. Proteins were prepared as described previously (Solomon 1985).

\subsection{Chromatography.}

Self-association properties of antibody light chains were evaluated by sizeexclusion chromatography, a technique by which reversible association is unambiguously revealed through differences in the elution behavior of protein samples applied to the column at different initial concentrations (Stevens 1980, 1989; Stevens et al. 1986; Myatt et al. 1991). Chromatography columns (3 mm $\times$ $25 \mathrm{~cm}$ ) were packed with Superose 12 (Pharmacia). Columns were run at a flow rate of $60 \mu \mathrm{l} / \mathrm{min}$. Sample size was $5 \mu \mathrm{l}$. Protein elution was monitored by absorbance at $214 \mathrm{~nm}$.

\subsection{Simulation.}

The simulation under development for analysis of the affinity and kinetics of interactions responsible for antibody light chain polymerization is similar to those we have previously described for analysis of other macromolecular interactions (Stevens 1980,1986,1989). The chromatography column was represented as a finite array of imaginary cells; the monomer, dimer, oligomer composition of each cell was calculated; migration of each constituent was accomplished by a Gaussian distribution in which the mean represented the average velocity of the constituent (cells/cycle) and the standard distribution introdur $=d$ dispersion of the sample.

Unlike the previous simulations, the current work involves two linked interac- 
tion reactions. The first reaction is that between two monomers $(M)$ to form one dimer $(D)$

$$
M+M \underset{k_{-1}}{\stackrel{k_{1}}{\rightleftharpoons}} D
$$

Dimers are the fundamental building block for oligomer $(\boldsymbol{O})$ formation.

$$
D+D \underset{k_{-2}}{\stackrel{k_{2}}{\rightleftharpoons}} O_{2}
$$

Higher order oligomers are formed by the addition of dimeric subunits.

$$
D+O_{n-1} \stackrel{k_{2}}{\rightarrow} O_{n}
$$

Dissociation of oligomers occurs with equal probability at each dimer-dimer junction within the polymer. Therefore, equimolar production of each of the possible dissociation products occurs.

$$
\frac{(n-1)}{2} \cdot O_{n} \underset{k_{-2}}{\longrightarrow} D+O_{2}+O_{3}+\ldots+O_{n-1}
$$

This model implicitly postulates that monomer formation can only occur by dissociation of dimers; thus, oligomer formation effectively stabilizes dimers.

\section{RESULTS AND DISCUSSION}

\subsection{Biomedical significance of light chain aggregation.}

The initial impetus for the study of biophysical aspects of antibody light chains that did not pertain to their immunochemical function resulted from a biomedical enigma. Many multiple myeloma patients experience complications that arise from tissue and organ deposition of these proteins (Glenner 1980a,b; 
Tubbs et al. 1981; Solomon 1982,1986; Solomon et al. 1991; Gallo et al. 1989; Stevens et al. 1991). These phenomena are idiosyncratic: not all patients experience complications and the physiological sites and expression of the pathologies vary among the patients who do experience light chain-related problems. Therefore, the relative contributions of host factors and protein-specific physicochemical factors are unclear.

Although both patient- and protein-related factors are probably involved to varying degrees in each individual's case, evidence for a causal relationship between protein structure and the expression of the complication was obtained with the finding that in cases of multiple myeloma associated with the production of the rare light chain subgroup, $\lambda_{\mathrm{VI}}$, amyloid seems to be invariably present (Solomon et al. 1982). Amyloid is a stable less commonly polymer formed by other light chains, and by several other proteins which share the $\boldsymbol{\beta}$-sheet structure characteristic of light chains. This suggested that the ability of light chains to polymerize, exhibited strikingly by $\lambda_{\mathrm{VI}}$ proteins, might be shared in varying degrees by other light chains as determined by individual amino acid substitutions. Thus, we used size-exclusion chromatography to examine the aggregation tendencies of light chains under various conditions of $\mathrm{pH}$, ionic strength, and buffer composition.

\subsection{Effect of solution conditions on light chain aggregation.}

Figure 2 compares the aggregation properties of a Bence Jones protein produced by a patient who experienced renal failure, a frequent outcome of the production of light chains. The upper panel demonstrates that the size distrib':tion of the light chain sample is effectively independent of concentration when tested under neutral pH conditions ( $50 \mathrm{mM}$ phosphate suffer, $100 \mathrm{mM} \mathrm{NaCl}, \mathrm{pH}$ 7.2), indicating that under these conditions, the interaction between light chain dimers is negligible. The lower panel displays the behavior of the same protein under a different set of solution conditions, $30 \mathrm{mM}$ acetate buffer at $2 \mathrm{H} 4.5$ 
$(250 \mathrm{mM} \mathrm{NaCl})$. Under these conditions, a shift to a significantly earlier elution position is found, revealing the presence of concentration-dependent aggregation of these light chains that is apparently induced by the increase in the proton concentration in the solvent. The elution position at minute 16 corresponds to a molecular weight appropriate for a light chain tetramer, presumably formed by the association of two dimers; the clear resolution between the apparent tetramer and the lower molecular weight components eluting later suggests that the Lissociation rate of the tetramer is slow (Stevens 1989). Variable domain fragments of this protein are also capable of forming tetrameric complexes under the same conditions (data not shown). At the highest protein concentration, aggregates that eluted at approximately minute 10 were observed. Because the molecular weight exclusion limit of a Superose 12 column is on the order of 200,000-300.000, it can be inferred that polymers comprising at least five light chain dimers were present in this sample and that they did not dissociate during the ten minutes required to transit the column.

Figure 3 indicates that low $\mathrm{pH}$ is not obligatory for the formation of high molecular weight light chain oligomers. In this instance, the light chain, obtained from a patient in which amyloid was present. demonstrated concentrationdependent aggregation under the neutral isotonic conditions in which the protein depicted in Figure 2 exhibited little or no polymerization. A significantly higher percentage of the Fig. 3 protein (compared to the light chain shown in Figure 2) eisted at the exclusion limit of the column, demonstrating a relatively higher propensity for the formation of oligomers. Moreover, the continuum of eluted protein that appears between the excluded volume position and the position corresponding to the dimer, the constituent considered the protomer for polymer formation, suggests a faster dissociation rate constant than that evident for the light chain in Figure 2.

The data shown in Figures 2 and 3 demonstrate the solvent-dependency of 
light chain aggregation and indicate that noncovalent polymers of extended size can be formed. These data are consistent with earlier findings of Neet and Putnam (1966) which indicated that at elevated temperatures, light chain polymers of molecular weight in excess of $10^{6}$ could be formed. To date, we have examined antibody light chains from more than $\mathbf{4 0}$ myeloma patients. Approximately one-half of these protein samples have exhibited polymerization tendencies under one or more of the solvent conditions in which they have been tested (Myatt et al., manuscript in preparation).

\subsection{Hypothetical mechanism of light chain polymerization.}

Figure 4 depicts our preliminary model for the interaction between light chain dimers that leads to oligomer formation. The rationale for the formation of this model arises from considerations of the properties of amyloid formed by antibody light chains and will be described in more detail elsewhere (Stevens et al., manuscript in preparation). Fundamentally, the concave surface of the variable domain dimer, which contains that portion of the molecule that contributes to the diverse antigen binding capabilities of antibodies, is structurally complementary to the concave surface that is found at the opposite pole of the structure. Therefore, depending upon the amino acid composition of these two surfaces, which varies for each protein obtained from individual patients, different affinities of interaction are found as well as different optimal solution conditions for interaction. The constant domain of the light chain, which is connected to the variable domain through an extended flexible peptide chain, neither contributes to nor blocks the polymerization mechanism illustrated in Figure 4.

\subsection{Light chains as a model system to study engineered protein assembly.}

Figure 4 represents a testable hypothesis to account for the spontaneous assembly of antibody light chains into high molecular weight aggregates. Several considerations suggest that this family of proteins will provide a unique model 
system within which to systematically study the structural basis of polypeptide assembly.

3.5.1 Structural data base. As indicated above, numerous crystallographic studies of antibody light chains of human origin have demonstrated the highly conserved nature of the three-dimensional structure of the $\boldsymbol{\beta}$-barrel domain. This conservation of structure has been further established by crystallographic studies of the antigen binding fragments of monoclonal antibodies. Therefore, interpretation of the functional properties of any antibody light chain is facilitated by fundamental confidence in the knowledge of its basic three-dimensional structure, even in the absence of a detailed crystallographic study.

3.5.2 Diversity. Because the evolution of immunoglobulin light chains was driven by the requirement for the generation of diversity in the antibody repertoire, it is probable that the combination of amino acid sequerice heterogeneity coupled with conserved basic three-dimensional structure can be equaled only by that of antibody heavy chains. Complete sequences of human light chain variable domains have been obtained from more than 140 patients (Kabat et al. (1987) and Solomon, personal communication). Assuming that the amino acid substitutions which have been documented to date all represent independent structurally permissible replacements, in excess of $10^{80}$ variant light chains can be constructed for study. Although a number of this magnitude is effectively meaningless, it assures that a broad spectrum of recombinant light chains is available.

3.5.3 Genetic engineering. The biomedical and biotechnological utility of monoclonal antibodies has motivated substantial progress in the cloning and bacterial production of antibody components in recent years (Boss et al. 1984; Cabilly et al. 1985,1989; Pluckthun et al. 1987; Better et al. 1988; Huston et al. 1988; Skerra et al. 1988; Condra et al. 1990; Glockshuber 1990a,b; Sharon 
1990). These methods can be used to produced large quantities of antibody light chains of predetermined amino acid sequence. Engineered light chains will be used to identify the surfaces of the molecule involved in formation of polymers. Subsequently, light chains which differ by single amino acid substitutions will provide the experimental data for the development of new computational tools for the engineering of specific protein-protein interactions.

3.5.4 $\boldsymbol{\beta}$-Domain assembly. The assembly capabilities of the $\boldsymbol{\beta}$-domain structure are widely expressed biologically. These structures are the basic building blocks of the so-called immunoglobulin superfamily, which includes the several classes of antibodies, $\beta-2$ microglobulin, the T-cell receptors, secretory components, the major histocompatability components, cell adhesion molecules, and neurological cell receptors (Williams 1984; Hunkapiller and Hood 1986; Williams an Barclay 1988). Driscoll et al. (1991) have recently determined the structure of the CD2 cell adhesion molecule, finding it to be conformationally homologous to the light chain variable domain, and consistent with the idea that the interactions between adhesion molecules of two interacting cells are mechanistically the same as the interactions between two light chain variable domains or between a light and a heavy chain variable domain. The $\boldsymbol{\beta}$ structure also appears to be a common featur a of many proteins that are capable of forming intractable amyloid fibrils. In addition to the antibody light chain, these include the antibody heavy chain, $\beta-2$ microglobulin, transthyretin (prealbumin), and serum amyloid-A protein. Reversible assembly of $\boldsymbol{\beta}$-domain subunits is a well-characterized feature of the protein capsids that shelter the RNA or DNA genomic component of viruses.

3.5 Role of computer simulation. The ability to systematically engineeer and utilize polypeptide subunits will involve extensive computational resources. Analysis of data such as illustrated in Fig. 2 and 3 will be dependent upon computer simulation to fit four rate constants if the most simple model representation is useful. The multiple protein interactions will be emulated numerically by cal- 
culating changes in the concentrations of discrete oligmer species during time intervals on the order of $0.001 \mathrm{~s}$ or smaller. Simulated data in Figure 5 schematically illustrate the dependence of elution profile on the magnitude of the affinity governing the polymerization reaction. However, because the MicroVax system used to generate this data does not have the speed necessary to complete a full-scale simulation, the chromatograms shown in Figure 5 are intended only to illustrate the sensitivity of elution profiles to the polymerization affinity; the transition from predominantly high-order molecular weight to minimal molecular weight occurs within a range of only two orders of magnitude. This corresponds to the free energy change that can be accomplished by substitutions of one to two amino acids at the appropriate locations.

Working simulations of the chromatographic behavior of interacting light chains will take advantage of the fact that the molecular events occuring simultaneously at two separated positions in the chromatography column are independent and therefore can be numerically mimicked simultaneously. This allows us to use the developing technology of massively parallel (concurrent) supercomputers such as the Intel Touchstone Delta machine, designed to provide 30 billion floating point operations per second distributed among more than 500 processors. Computers capable of more than one trillion floating point operations, and even faster descendents, will likely provide the means to dynamically model proteinprotein interactions and to predict the consequences of amino acid substitution that can be experimentally measured by chromatography and other means. 


\subsection{CONCLUSION}

The multiple association mechanisms of antibody light chains have not yet been fully characterized. The formation of dimers by light chains is determined by interactions between $\boldsymbol{\beta}$-sheets. Polymerization of light chain dimers is hypothesized to be controlled by interactions between the loops which connect $\boldsymbol{\beta}$-strands. Additional interactions, which might contribute to the formation of amyloid fibrils, and may be analogous to interactions involved in the assembly of viral capsids, may also involve $\boldsymbol{\beta}$-sheet interactions. Because these multiple interaction capabilities are sensitively linked to substitutions of specific amino acids, which remain to be determined, and because the affinity of these interactions can be changed by manipulation of solution conditions, it is clear that the diverse array of $\boldsymbol{\beta}$-domain modules provided by antibody light chains represents a rich resource for study of the fundamental principles of controlled polypeptide assembly.

\section{ACKNOWLEDGEMENTS}

This work was supported by the United States Department of Energy, Office of Health and Environmental Research, under Contract W-31-109-ENG-38. We are grateful to T.J. O'Donnell and K.F. Koehler (Searle) for preparation of the molecular graphics images in Figures 1 and 4. 


\section{FIGURE LEGENDS}

Figure 1. Backbone representation of a typical antibody light chain variable domain dimer. Coordinates of protein Rei (Epp et al. 1974,1975) were obtained from the Brookhaven Protein Data Bank.

Figure 2. Size-exclusion chromatograms illustrating solution-dependence of polymerization properties. Upper Panel: $50 \mathrm{mM} \mathrm{NaPO}, 100 \mathrm{mM} \mathrm{NaCl}, \mathrm{pH} 7.2$; approximate protein concentrations $4 \mathrm{mg} / \mathrm{ml}(-), 2 \mathrm{mg} / \mathrm{ml}(\cdots), 1 \mathrm{mg} / \mathrm{ml}$ (- - ), $0.5 \mathrm{mg} / \mathrm{ml}(--)$. Lower Panel: Acetate buffer, $\mathrm{pH} \mathrm{4.5;} \mathrm{approximate}$ protein concentrations $5 \mathrm{mg} / \mathrm{ml}(\longrightarrow), 1 \mathrm{mg} / \mathrm{ml}(\cdots), 0.5 \mathrm{mg} / \mathrm{ml}(--)$ ).

Figure 3. Size-exclusion chromatographic demonstration of high-order aggregation under neutral conditions (buffer as in upper panel of Figure 1). Protein concentrations $2.5 \mathrm{mg} / \mathrm{ml}\left({ }_{-}\right), .25 \mathrm{mg} / \mathrm{ml}(\cdots), 0.02 \mathrm{mg} / \mathrm{ml}(--)$.

Figure 4. Hypothetical model of light chain polymerization. Adjacent light chain variable domain dimers are related by an approximate $90^{\circ}$ rotation about the twofold symmetry axis which relates the two identical monomers in the dimer. Dual salt bridges contributed by suitably located amino acids of opposite charge present on many, but not all, light chains are highlighted. The constant domains, which do not contribute to the polymerization process in this model, are not shown.

Figure 5. Simulated elution profiles. Descending panels represent consecutive tenfold decreases in the affinity of polymerization between light chain dimers. 
[1] Abola E E, Ely K R, and Edmundson A B 1980 Marked structural differences of the Mcg Bence Jones dimer in two crystal structures. Biochemistry 19 432-439

[2] Better M, Chang C P, Robinson R R, and Horwitz A H 1988 Escherichia coli secretion of an active chimeric antibody fragment. Science $2401041-$ 1043

[3] Boss M A, Kenten J H, Wood C R, and Emtage J S 1984 Assembly of functional antibodies from immunoglobulin heavy and light chains synthesised in E. coli. Nucleic Acid Res. 12 3791-3806

[4] Cabilly S, Riggs A D, Pande H, Shively J E, Holmes W E, Rey M, Perry L J, Wetzel R, and Heyneker H L 1985 Generation of antibody activity from immunoglobulin polypeptide chains produced in Escherichia coli. Proc. Natl. Acad. Sci., USA 81 3273-3277

[5] Cabilly S 1989 Growth at sub-optimal temperatures allows the production of functional, antigen-binding Fab fragmnts in Escherichia coli. Gene 85 553-557

[6] Chang C-H, Short M T, Westholm F A, Stevens F J, Wang B-C, Furey W, Solomon A, and Schiffer M 1985 Novel arrangement of immunoglobulin variable domains: $X$-ray crystallographic analysis of the lambda-chain dimer Bence Jones protein Loc. Biochemistry 24 4890-4897

[7] Chothia C, Lesk A M, Tramontano A, Levitt M, Smith-Gill S J, Air G, Sheriff S, Padlan E A, Davies D R, Tulip W R, Colman P M, Spinelli S, Alzari P $M$, and Poljak, R J 1989 Conformations of immunoglobulin hypervariable regions. Nature $342877-883$ 
[8] Colman P M, Schramm H J, and Guss J M 1977 Crystal and molecular structure of the dimer of variable domains of the Bence Jones protein Roy. J. Mol. Biol. 116 73-79

[9] Condra J H, Sardana V V, Tomassini J E, Schlabach A J, Davies M-E, Lineberger, D W, Graham D J, Gotlib L, and Colonno R J 1990 Bacterial expression of antibody fragments that block human rhinovirus infection of cultured cells. J. Biol. Chem. 265 2292-2295

[10] Davies D R, Padlan E A, and Sheriff S 1990 Antibody-antigen complexes. Ann. Rev. Biochem. 59 439-473

[11] Driscoll P C, Cyster J G, Campbell I D, and Williams A F 1991 Structure of domain 1 of rat T lymphocyte CD2 antigen. Nature 353 762-765

[12] Ely K R, Wood M K, Rajan S S, Hodson J M, Abola E E, Deutsch H F, and Edmundson A B 1985 Unexpected similarities in the crystal structures of the Mcg light-chain dimer and its hybrid with the Weir protein. Mol. Immunol. 22 93-100

[13] Ely K R, Herron J N, Harker M, and Edmundson A B 1989 Threedimensional structure of a light chain dimer crystallized in water. Conformational flexibility of a molecule in two crystal forms. J. Mol. Biol. 210 601-615

[14] Epp O, Colman P M, Fehlhammer H, Bode W, Schiffer M, Huber R, and Palm W 1974 Crystal and molecular structure of a dimer composed of the variable portions of the Bence Jones protein Rei. Eur. J. Biochem. 45 513-524

[15] Epp O, Lattman E E, Schiffer M, Huber R, and Palm W 1975 The molecular structure of a dimer composed of the variable portions of the Bence Jones protein Rei refined at 2.0 A resolution. Biochemistry $144943-4952$ 
[16] Fehihammer $H$, Schiffer M, Epp O, Colman P M, Lattman E E, Schwager $P$, and Steigemann $W 1975$ The structure determination of the variable portion of the Bence Jones protein Au. Biophys. Struct. Mechanism 1 139-146

[17] Furey W, Wang B-C, Yoo C S, and Sax M 1979 Phase extension and refinement of Bence Jones protein Rhe (1.9 A). Acta Cryst. A35 810-817

[18] Furey W, Wang B-C, Yoo C S, and Sax M 1983 Structure of a novel Bence Jones protein (Rhe) fragment at 1.6 Angstrom resolution. J. Mol. Biol. 167 661-692

[19] Gallo G R, Picken M, Buxbaum J N, and Frangione B 1989 The spectrum of monoclonal immunoglobulin deposition disease associated with immunocytic dyscrasias. Sernin. Hematol. 26 234-245

[20] Glenner G G 1980a Amyloid deposits and amyloidosis. The $\beta$-fibrilloses. (First of two parts.). New Eng. J. Med. 302 1283-1292

[21] Glenner G G 1980b Amyloid deposits and amyloidosis. The $\boldsymbol{\beta}$-fibrilloses. (Second of two parts.). New Eng. J. Med. 302 1333-1343

[22] Glockshuber R, Malia M, Pfitzinger I, and Pluckthun A 1990a A comparison of strategies to stabilize immunoglobulin $F_{V}$ fragments. Biochemistry 29 1362-1367

[23] Glockshuber R, Steipe B, Huber R, and Pluckthun A 1990b Crystallization and preliminary $x$-ray studies of the $V_{L}$ domain of the antibody $M_{C} P C 603$ produced in Escherichia coli. J. Mol. Biol. 213 613-615

[24] Hunkapiller $T$ and Hood L 1986 The growing immunoglobulin superfamily. Nature 323 15-16 
[25] Huston J S, Levinson D, Mudgett-Hunter M, Tai M-S, Novotny, J, Margolies M N, Ridge R R, Bruccoleri R E, Haber E, Crea R, and Oppermann, H 1988 Protein engineering of antibody binding sites: recovery of specific activity in an anti-digoxin single-chain Fv analogue produced in Escherichia coli. Proc. Natl. Acad. Sci., USA 85 5879-5883

[26] Jones, H Bence 1847 Papers on chemical pathology. Lecture III. Lancet 2 88-92

[27] Jones, $H$ Bence 1848 On a new substance occurring in the urine of a patient with mollities ossium. Phil. Trans. R. Soc. London 55-62

[28] Kabat E A, Wu T T, Reid-Miller M, Perry H M, and Gottesman K S 19887 Sequences of Proteins of Immunological Interest. U.S. DHHS, National Institutes of Health.

[29] Maeda H, Engel J, and Schramm H J 1976 Kinetics of dimerization of the variable fragment of the Bence Jones protein Au. Eur. J. Biochem. 69 133-139

[30] Maeda H, Steffan E, and Engel J 1978 Kinetics of dimerization of the Bence Jones protein Au. Biophys. Chem. 9 57-64

[31] Myatt E A, Stevens F J, and Sigler P B 1991 Effects of pH and calcium ion on self-association properties of two dimeric phospholipases $A_{2}$. J. Biol. Chem. 266 16331-16335

[32] Neet K E and Putnam F W 1966 Characterization of the thermal denaturation of Bence Jones proteins by ultracentrifugation at elevated temperatures. J. Biol. Chem. $2412320-2325$ 
[33] Pluckthun A, Glockshuber R, Pfitzinger I, Skerra A, and Stadlmuller J 1987 Engineering of antibodies with a known three-dimensional structure. Cold Spring Harbor Symp. Quant. Biol. 52 105-112

[34] Schiffer M, Girling R L, Ely K R, and Edmundson A B 1973 Structure of a lambda-type Bence Jones protein at $3.5 \AA$ resolution. Biochemistry 124 4620-4631

[35] Schiffer M, Ainsworth C, Xu Z-B, Carperos W, Olsen K, Solomon A, Stevens $F J$, and Chang C-H 1989 Structure of a second crystal form of Bence Jones proein Loc: strikingly different domain associations in two crystal forms of a single protein. Biochemistry $284066-4072$

[36] Sharon J 1990 Structural correlates of high antibody affinity: three engineered amino acid substitutions can increase the affinity of an anti-pazophenylarsonate antibody 200-fold. Proc. Natl. Acad. Sci. 87 4814-4817

[37] Skerra A and Pluckthun A 1988 Assembly of a functional immunoglobulin $F_{V}$ fragment in Escherichia coli. Science 240 1038-1041

[38] Solomon A 1982 Bence Jones proteins: Malignant or benign? New England J. Med. 306 605-607

[39] Solomon A, Frangione B, and Franklin E C 1982 Bence Jones proteins and light chains of immunoglobulins. Preferential association of the $V_{\lambda} V I$ subgroup of human light chains with amyloidosis $\mathrm{AL}(\lambda)$. J. Clin. Invest. $70453-460$

[40] Solomon A 1985 Light chains of human immunoglobulins. Meth. Enzymol. 116 101-121

[41] Solomon A 1986 Clinical implications of monoclonal light chains. Semin. Oncol. 13 341-349 
[42] Solomon A, Weiss D T, and Kattine A A 1991 Nephropathological potential of human Bence Jones proteins: Experimental and clinical correlates. $N$. Engl. J. Med. 324 1845-1851

[43] Stevens F J, Westholm F A, Solomon A, and Schiffer M 1980 Selfassociation of human immunoglobulin $\kappa I$ light chains: role of the third hypervariable region. Proc. Natl. Acad. Sci. USA 77 1144-1148

[44] Stevens F J and Schiffer M 1981 Computer simulation of protein selfassociation during small-zone gel filtration: estimation of equilibrium constants. Biochem. J. 195 213-219

[45] Stevens F J 1986 Analysis of protein-protein interaction by simulation of small-zone size-exclusion chromatography: application to an antibodyantigen association. Biochemistry 25 981-993

[46] Stevens F J, LeBuis D, Eisler W, and Ainsworth C 1986 Macromolecular interactions: application of microcomputer-controlled, high speed sizeexclusion chromatography. LCGC 4 340-348

[47] Stevens F J, Chang C-H, and Schiffer M 1988 Dual conformations of an immunoglobulin light chain dimer: heterogeneity of antigen specificity and idiotope profile may result from multiple variable-domain interaction mechanisms. Proc. Natl. Acad. Sci., U.S.A. 85 6895-6899

[48] Stevens F J 1989a Analysis of protein-protein interaction by simulation of small-zone size-exclusion chromatography: Stochastic formulation of kinetic rate contributions to observed HPLC elution characteristics. Biophys. J. 155 1155-1167

[49] Stevens F J 1989b Applications of size-exclusion HPLC in the analysis of protein and peptide epitopes. Meth. Enzymol. 178 107-130 
[50] Stevens F J, Solomon A, and Schiffer M 1991 Bence Jones proteins: a powerful tool for the fundamental study of protein chemistry and pathophysiology. Biochemistry $306803-6805$

[51] Tubbs R, Gephardt G, McMahon J, Hall P, Valenzuela R, and Vidt D 1981 Light chain nephropathy. Am. J. Medicine. 71 263-269

[52] Williams A F 1984 The immunoglobulin superfamily takes shape. Nature 308 12-13

[53] Williams A F and Barclay A N 1988 The immunoglobulin superfamily domains for cell surface recognition. Ann. Rev. Immunol. 6 381-405 


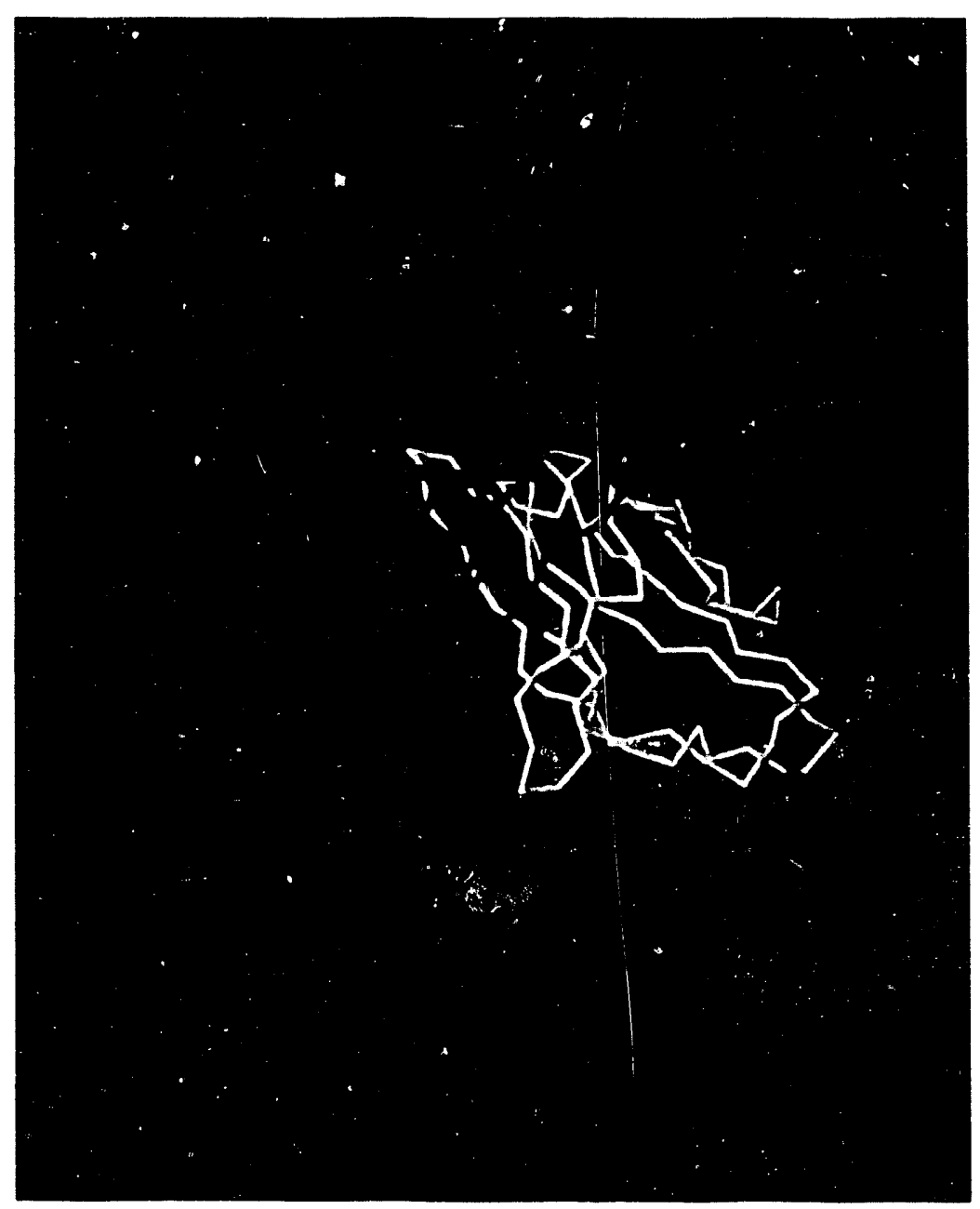



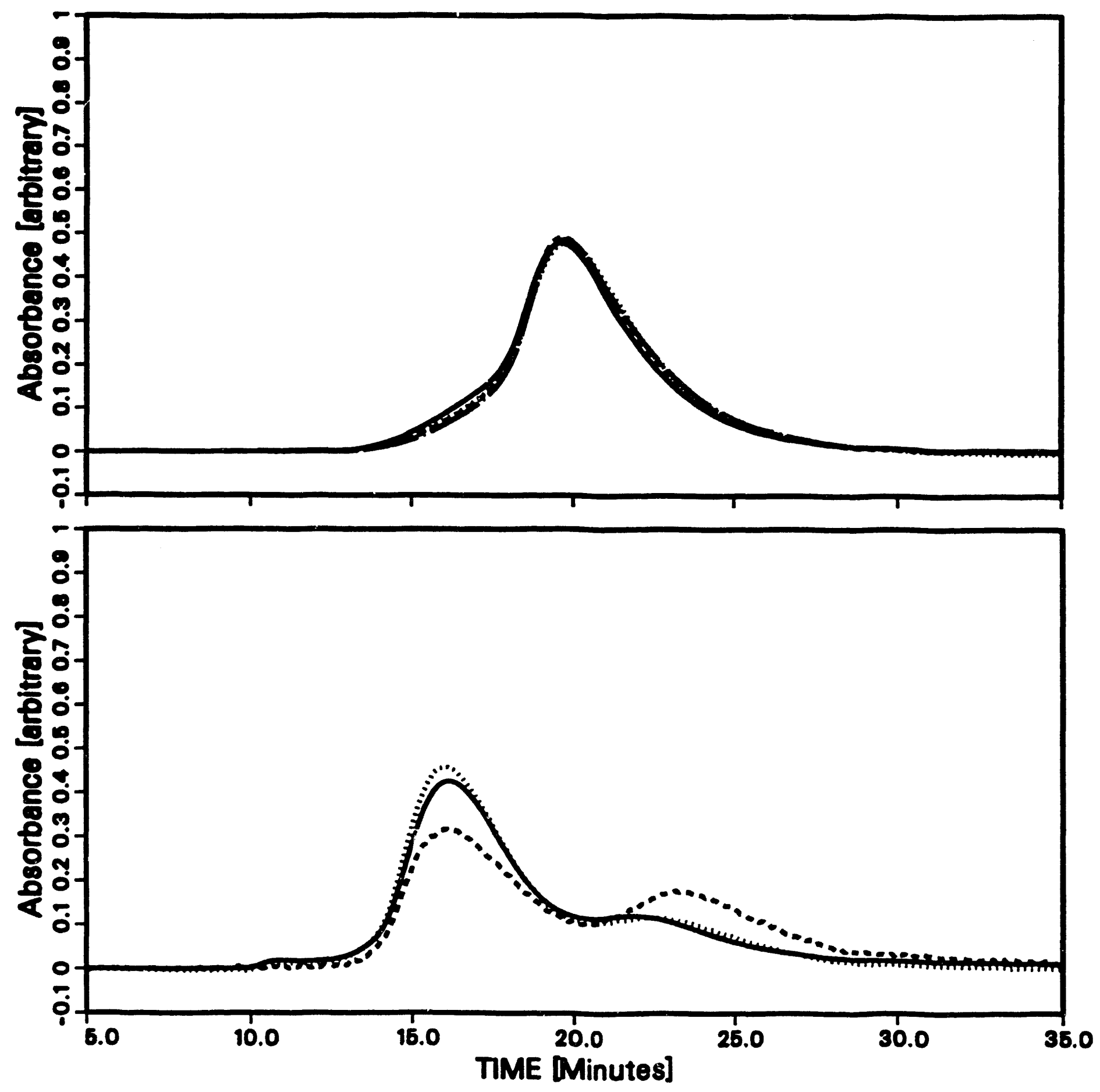


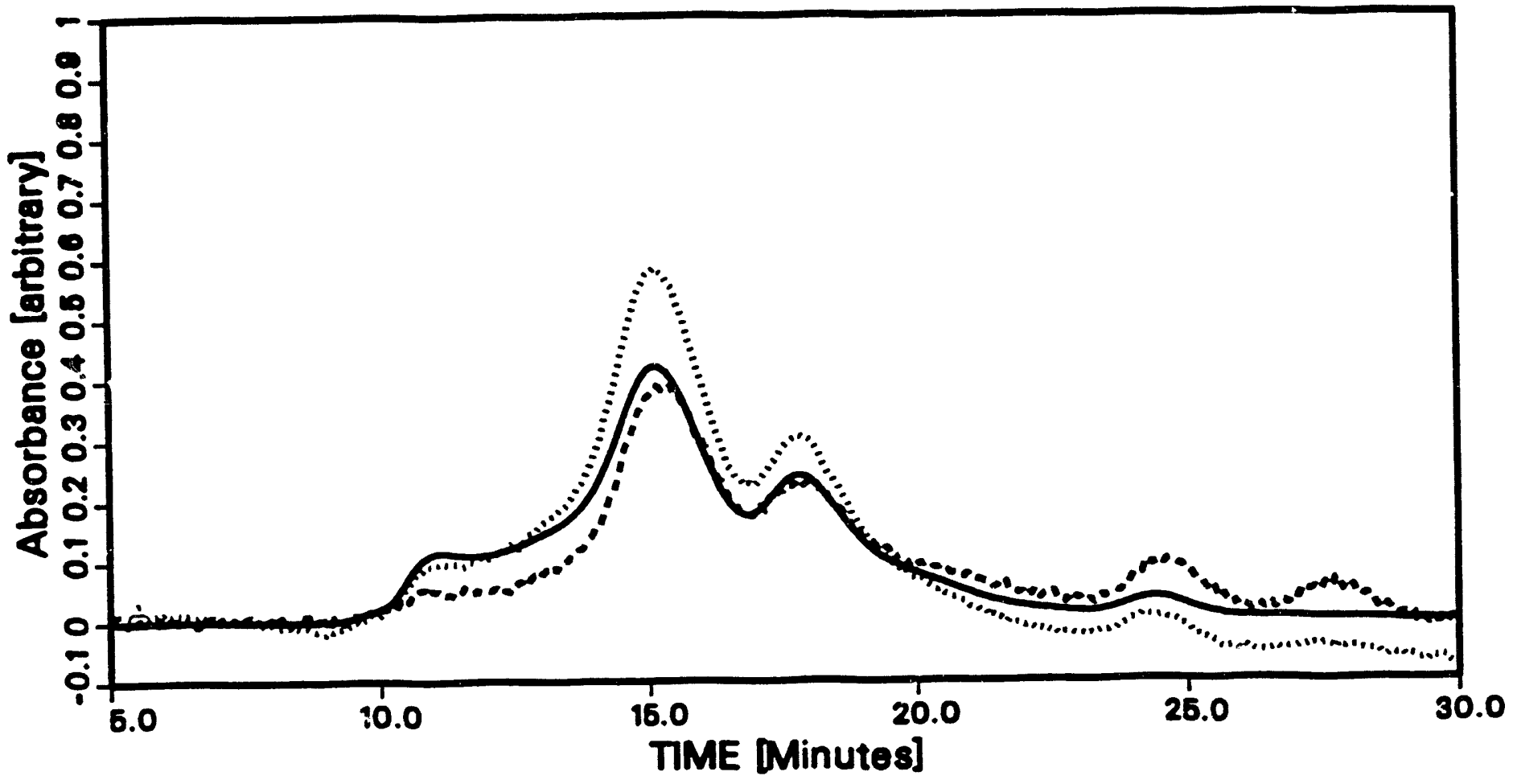




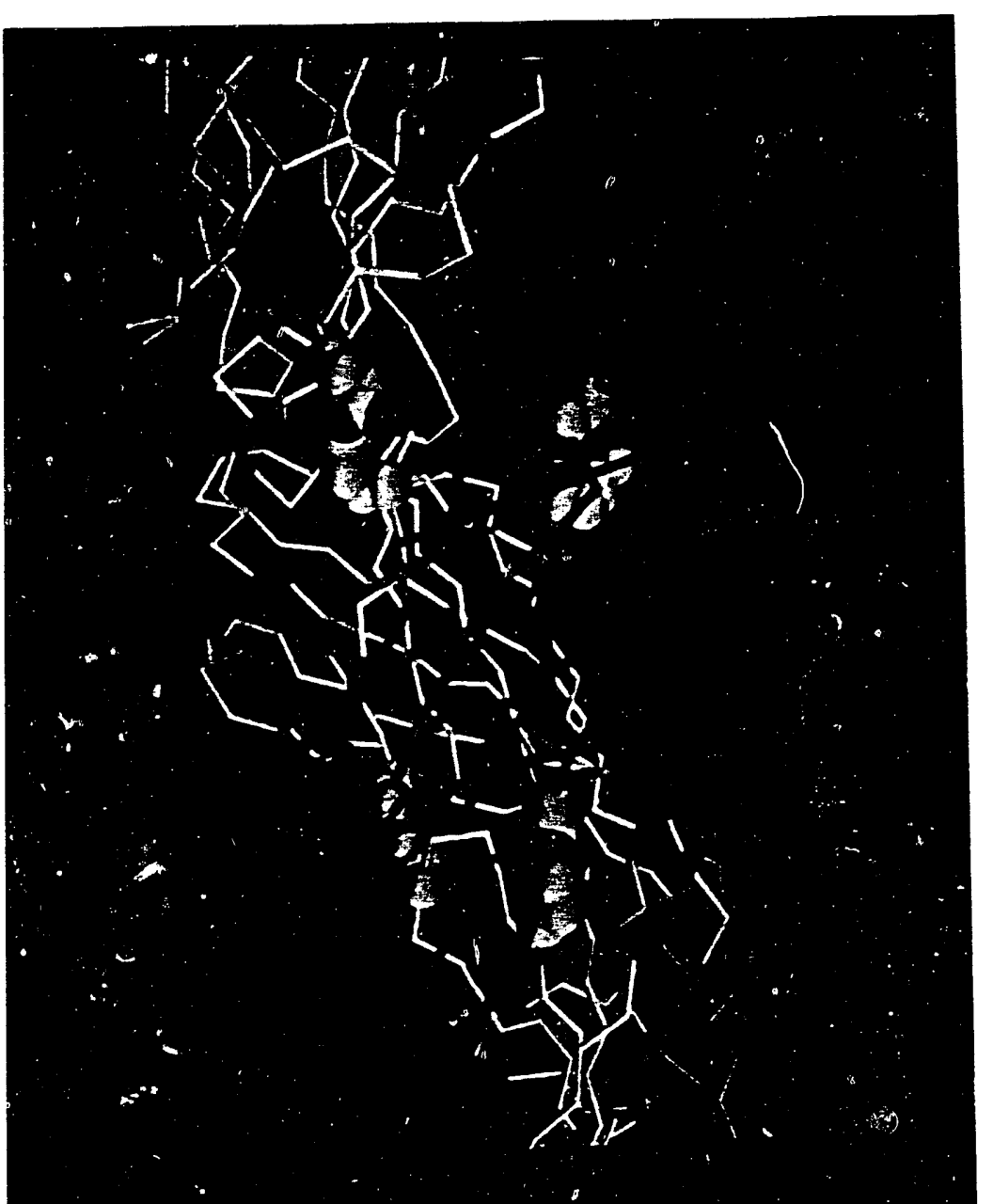




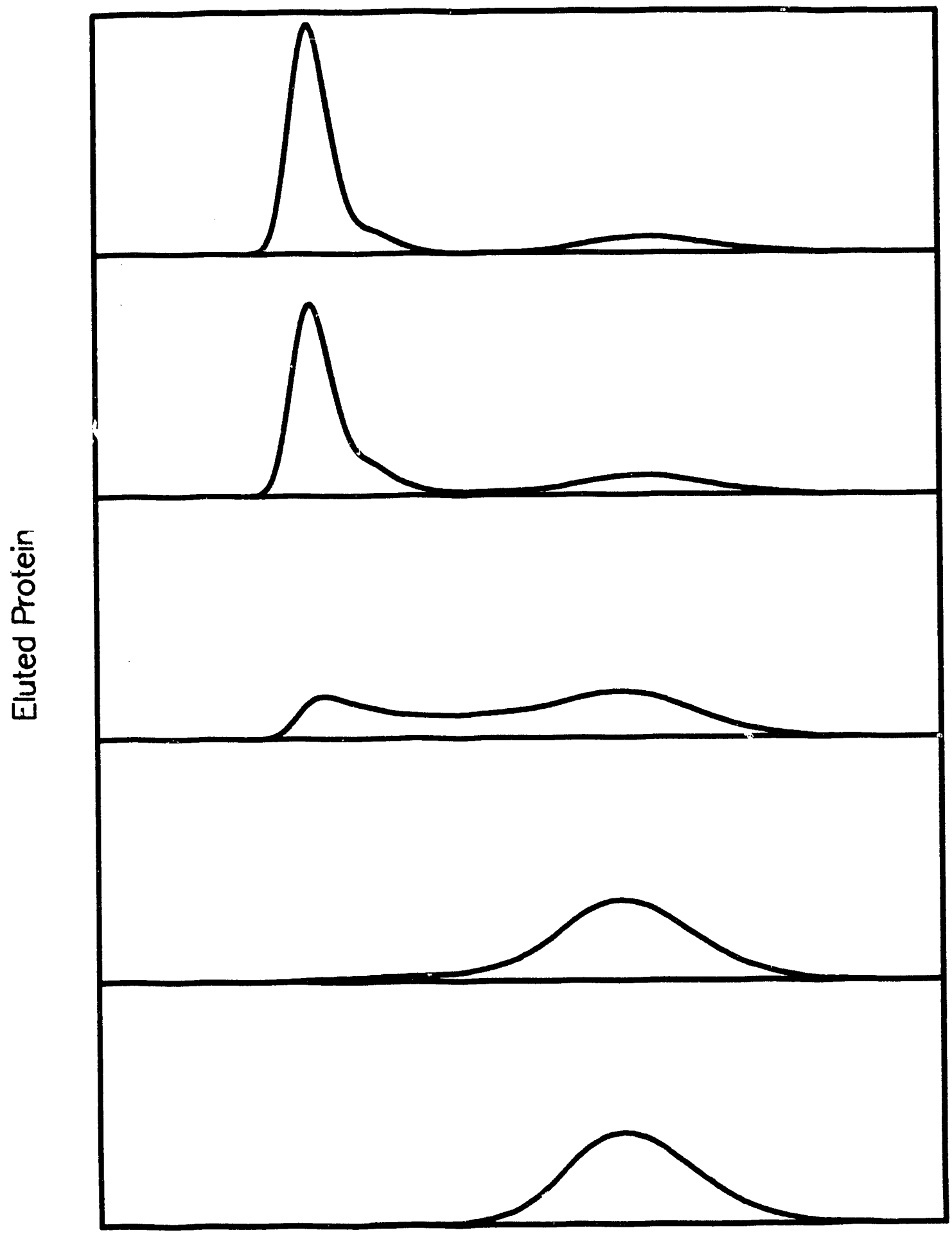

Elution Time 

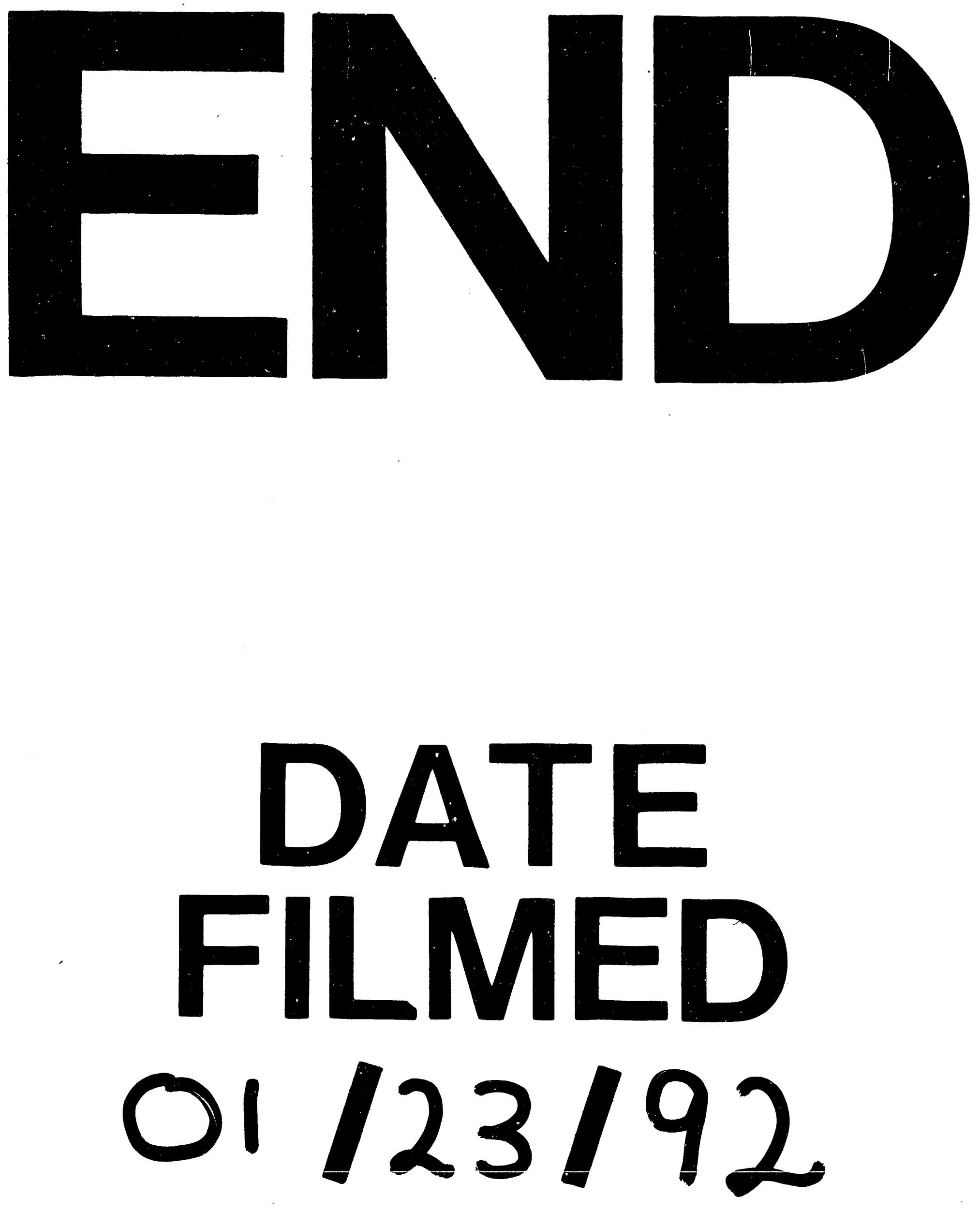
$\because$ 